\title{
The Ambiguity of Musical Expression Marks and the Challenges of Teaching and Learning Keyboard Instruments: The Nnamdi Azikiwe University Experience
}

\author{
Ikedimma Nwabufo Okeke \\ http://dx.doi./org/10.4314/ujah.v18i1.7
}

\section{Abstract}

The relevance of musical expression marks - technical words, symbols, phrases, and their abbreviations - in music is to guide the performer through a thorough interpretation and appreciation of the dynamics and subtleties of a piece of music. These marks, though fundamental to piano pedagogy, sometimes appear confusing to the enthusiastic piano student owing to the fact that some of the performance marks demand subjective expressions from the performer such as, 'furiously', 'fiercely' 'with agitation' 'brightly', tenderly, etc. Piano-keyboard education is still a 'tender' art in Nigerian higher institutions where most learners start at a relatively very late age (17-30 yrs) and so, it becomes burdensome and sometimes unproductive to encumber the undergraduate piano-keyboard student with a plethora of performance marks when he is still grappling with scales and arpeggios. This paper therefore suggests teaching keyboard basics and technique and employing fundamental musical expression marks/dynamics first for undergraduate piano teaching and learning in our institutions. Only when students have shown competences in the basic dynamiclexpression marks such as, crescendo, accelerando, andante, moderato, allegro, larghetto etc, can the more complex and subjective ones be introduced in their keyboard repertoire. 


\section{Introduction}

The New Harvard dictionary of Music (2001) defines musical expression/performance marks as 'symbols and words or phrases and their abbreviations employed along with musical notation to guide the performance of a work in matters other than pitches and rhythms'. These marks in general affect dynamics, tempo, and articulation. Performance marks also have been defined as, 'Words, abbreviations, and symbols employed along with the notation of pitch and duration to indicate aspects of performance (The New Harvard dictionary of Music, 2001). These marks also may be tempo indications, dynamic marks, technical instructions, marks for phrasing and articulation, and designations for the character of the piece or section. Expression/performance marks may be used synonymously in music.

These expression/performance marks punctuate virtually all forms of music (vocal/instrumental/orchestral/ensemble, etc.), and particularly piano music. Piano teaching/learning also is a basic feature of undergraduate studies. Even when students feature in other instrumental/orchestral studies and performances, piano practice and playing is compulsory! The curriculum of music studies is designed to feature 'Keyboard studies' as a preliminary and preparatory course for piano playing. This makes piano teaching/learning a serious issue in the higher institutions and one of the major challenges to this goal is the problem of 'overnotation': a situation where expression/performance marks blur proper interpretation and appreciation of music.

\section{The Piano and its History with Musical Dynamics}

The piano was born out of the quest to have a keyboard instrument capable of yielding subtle degrees of soft (piano) and loud (forte) dynamics by mere varying of the pianist's finger pressure. Because 
earlier keyboard instruments (clavichord, harpsichord, pipe organ, spinet, etc) that were in use around the $14^{\text {th }}$ century could not deliver these subtleties in dynamics, the piano - a novelty of the $17^{\text {th }}$ century - became renowned. The piano actually derived its name from this capability of rendering soft-loud (piano-forte), or loud-soft (forte-piano) dynamics, hence the original names of the instrument, piano-forte or forte-piano(Wikipedia Encyclopedia, 2013).

Given the dynamic nature of the piano and its fame during the Classical period, ambitious composers of the neo-classical, Romantic, and the modern era experimented more on the capability of the instrument; composing and performing works that could capture the expressive powers of the instrument to the fullest. Franz Listz, for example, was famed for making the piano 'sing' at his touch (Kamien, 1986). These composers, as it were, demanded versatility from the instrument. The novelty that the piano could yield subtle dynamics ( $p, p p, p p p, f, f f, f f f)$ by mere finger manipulations seemed to have mesmerized Neo-Classical, Romantic and Modern composers a lot. From these eras came various compositions with unusual, highly subjective and exotic dynamics and performance/expression marks such as, gracefully, with feeling, majestically, with fury, with fire, etc. Some of the fundamental and traditional dynamic markings such as, piano, forte, fortissimo, crescendo, diminuendo, ritardando etc, appeared to have lost cognizance. It was as if the entire performance dynamics of every musical work were at the 'pleasure' of the pianist.

Romanticism (1820-1900), a school of thought and also a period in the arts, came with a cultural movement that stressed emotion, imagination, and individualism (Kamien, 1986). Kamien (1986) further explained that: 
In part, Romanticism was a rebellion against the neoclassicism of the eighteenth-century and the age of reason. Romantic writers broke away from time-honoured conventions and emphasized freedom of expression. Painters used bolder, more brilliant colours and preferred dynamic motion to gracefully balanced poses (p.294).

Emotional subjectivity was the hallmark of the Romantic spirit! The New Harvard dictionary of Music (2001) captures the Romantic style more appropriately thus, 'Romantic thus came to signify freedom from the Classical tradition and, in its place, the uncontrolled play of the individual creative imagination, with resulting connotations of the highly idiosyncratic and even the fantastic'. The influence of the Romantic style on music is so conspicuous that one cannot describe or analyze Romantic music without recourse to its unprecedented emphasis on self expression and individuality of style. There was also a universe of feeling that included flamboyance and intimacy, unpredictability and melancholy.

\section{Analysis of Some Fundamental Musical Expression/Performance Marks}

Table 1(a):Words Showing Strength of Tone

\begin{tabular}{|l|l|}
\hline \multicolumn{1}{|c|}{ Expression } & \multicolumn{1}{|c|}{ Interpretation } \\
\hline Pianissimo $(\mathrm{pp})$ & Very soft \\
\hline Mezzo piano $(\mathrm{mp})$ & Moderately soft \\
\hline Piano $(\mathrm{p})$ & Soft \\
\hline Mezzo voce $(\mathrm{mv})$ & Medium tone \\
\hline Mezzo forte $(\mathrm{mf})$ & Moderately loud \\
\hline Forte $(f)$ & Loud \\
\hline
\end{tabular}




\begin{tabular}{|l|l|}
\hline Fortissimo $(f f)$ & Very loud \\
\hline Crescendo or $<$ & Gradually becoming louder \\
\hline Decrescendo/Diminuendo or $>$ & Gradually becoming softer \\
\hline Sforzando $(s f) /$ Forzando $(f)$ & Accented \\
\hline Reinforzando $(r f)$ & Strengthening the tone \\
\hline
\end{tabular}

Table 1(b): Words Showing Speed

\begin{tabular}{|l|l|}
\hline \multicolumn{1}{|c|}{ Expression } & \multicolumn{1}{c|}{ Interpretation } \\
\hline Grave & Extremely slow, solemn \\
\hline Lento & Slow \\
\hline Largo & Broad \\
\hline Larghetto & Rather broad \\
\hline Adagio & Slow, leisurely \\
\hline Andante & Going at an easy pace \\
\hline Andantino & $\begin{array}{l}\text { At } \text { a moderate pace, but as } \\
\text { slow as andante }\end{array}$ \\
\hline Moderato & Moderate speed \\
\hline Allegretto & Rather fast \\
\hline Allegro & Fast \\
\hline Vivace & Lively \\
\hline Presto & Very quick \\
\hline Prestissimo & As fast as possible \\
\hline Accelerando & Getting gradually faster \\
\hline Rallentando & Getting gradually slower \\
\hline Ritardando & Retarding the speed \\
\hline
\end{tabular}


Although some of the fundamental expression marks above show some degree of subjectivity and vagueness in interpretation like vivace (lively), but the rest of the expression marks are relatively clear and objectively interpretable. Vivace is vague in the sense that it demands the involvement of the performer's mood: it takes a lively mood to play in a lively manner. Also what degree of liveliness is required for the precise realization of the term vivace?. However, a unique instrument that could measure accurately the speed of a piece of music was developed by Johann Nepomuk Maezel (1772-1838). This instrument is called the Maelzel Metronome. The instrument is pyramid shaped, contains a mechanism based on the principle of the double pendulum, i.e., an oscillating rod with a eight at each end, the upper weight being movable along a scale.

Clockwork maintains the motion of the rod and provides the ticking. By adjusting the movable weight away from or toward the axis, the pendulum's swinging and the ticking, can be made slower or faster, respectively. Some modern electric metronomes do not rely on a pendulum, frequently supplementing or replacing the ticking with a blinking light (The New Harvard dictionary of Music (2001). The pendulum beats so many times in a minute, according to the figure to which the sliding weight is set. If the weight is set to the figure 60, the pendulum will beat 60 times in a minute, that is, once a second. If, for example, we see the 'metronome mark' crotchet $=126$, it means that the sliding weight should be set at the figure 126, when the pendulum, on being set in motion, will show the speed of the crotchets- 126 in a minute (A Handbook of Musical Knowledge, 1972). 


\section{Analysis of Some Vague and Subjective Musical Expression/Performance Marks}

\section{Table 2: General Expressions}

\begin{tabular}{|l|l|}
\hline Expression & Possible Interpretation \\
\hline Agitato & in an agitated manner \\
\hline Animato & Animated \\
\hline Appassionato & Impassioned \\
\hline Cantabile & in a singing style \\
\hline Capriccioso & Fanciful \\
\hline Con anima & with soul \\
\hline Con brio & with vivacity \\
\hline Con expression & with expression \\
\hline Con energia & with energy or force \\
\hline Confuoco & With fire \\
\hline con grazia & with grace \\
\hline Con moto & with motion \\
\hline Con spirit & with spirit \\
\hline Con tenerezza & with tenderness \\
\hline Deciso & Decided \\
\hline Delicato & Delicately \\
\hline Dolce & Sweetly \\
\hline Energico & in an energetic manner \\
\hline Espressivo & Expressively \\
\hline Forza & Force \\
\hline Furioso & with fury \\
\hline Grandioso & Grandly \\
\hline Grazioso & Gracefully \\
\hline Leggirro & Lightly \\
\hline Maestoso & Majestic \\
\hline & \\
\hline & an \\
\hline
\end{tabular}




\begin{tabular}{|l|l|}
\hline Martellato & with great force \\
\hline Mesto & in a pensive, sad manner \\
\hline Pesante & Heavily \\
\hline Piacevole & In a pleasing manner \\
\hline Pomposo & Pompously \\
\hline Risoluto & in a resolute manner \\
\hline Rubato & Robbed \\
\hline Scherzando & in sprightly, playful manner \\
\hline Serioso & Seriously \\
\hline Sonore & Sonorous \\
\hline Sotto voce & in a subdued manner \\
\hline Teneramente & Tenderly \\
\hline Tranquillo & Tranquilly \\
\hline
\end{tabular}

The list is inexhaustible! Several of these exotic expression marks, though still relevant to music or piano interpretation, but one wonders how many pianists that can memorize all of them, how much more applying them appropriately.

\section{Some Fundamental Principles of Piano Pedagogy}

Piano pedagogy is the study of the teaching/learning of piano playing (Wikipedia Encyclopedia, 2014). The preoccupation of the piano teacher is to find the best principles and approaches that can yield the best results in his art. He makes sure the learner is engaged in the appropriate path to competence by organizing the content of study appropriately. This is done most often through formal or private instructions referred to as piano lessons. What is the basic content of piano studies and what actually is the piano teacher expected to teach? Piano pedagogy actually involves the study of the teaching of the motor, intellectual, problem solving, 
and artistic skills involved in playing the piano effectively (Wikipedia Encyclopedia, 2014). This integrates many aspects of music, for example:

Ear training- This involves listening to quality performances of 'descriptive and strikingly expressive music', as a means of sensitizing the student to the meaning of music (music appreciation).

Rhythm- Teaching rhythm is important for the student to be able to learn a piece accurately, but also important for students to confidently perform a practical piece. The importance of having an internal metronome plays a huge part when teaching rhythm.

Technique- Good piano playing technique involves the simultaneous understanding in both the mind and the body of the relationship between the elements of music theory, recognition of musical patterns in notation and at the fingertips, the physical landscape of the entire range of the keyboard, finger dexterity and independence, And a wide range of touch and tone production for a variety of emotional expressions. Skills in all of these areas should always be nurtured and developed for the sake of expressing oneself more effectively and naturally through the sound of the piano, so that the elements of technique would sound alive with musicality.

Sight reading- Sight- reading heavily depends on the students' ability to understand rhythm, and recognize musical patterns. Teaching sight-reading can include teaching students to recognize intervals, scale passage patterns, note reading and the ability to internalize rhythm.

Memorization- Memorization is often needed when students want to perform a piece confidently. It gives the student ability and 
freedom to experience the music for all of its intricate musicality opposed to focusing on the technicality of notes and rhythm.

Improvisation- The modern trend of piano lessons tends to lean toward an overemphasis on learning notation, and neglects the nurturing needed for developing the creative spirit and sensitive ears which lead to expressive music-making. Studies point to the need for using multiple approaches in learning musical skills which engage both sides of the brain- the analytical and the intuitive- for students to master all aspects of playing. Therefore, teaching improvisation skills may help students take ownership of the expressive quality of the music they make, and to keep music learning and practicing alive and interesting.

The interpretation of expression and performance marks, though an aspect of 'piano technique', was not highlighted among the fundamental contents of piano pedagogy. This does not imply that it is irrelevant but that it is secondary. If the piano tutor ignores the fundamentals of ear training, rhythm, improvisation, memorization, technique, etc, and jumps to performance dynamics and their interpretation, the entire endeavour is bound to be unproductive.

\section{Applying Learning Theories to Piano Pedagogy}

Several learning theories that apply to piano abound but one remarkable type of learning crucial to piano pedagogy is the 'competency-based learning'. This is a type of learning that suggests the presentation of learning in strata, that is, in stages of simple- intermediate- difficult, and not the other way round. The Wikipedia Encyclopedia (2013) describes Competency-based learning thus:

Competency-based learning or competency-based education and training is an approach to teaching and 
learning more often used in learning concrete skills than abstract learning. It differs from other non-related approaches in that the unit of learning is extremely fine grained. Rather than a course or a module, every individual skills/learning outcome known as a competency is one single unit. Learners work on one competency at a time, which is likely a small component of a larger learning goal. The student is evaluated on the individual competency, and only once they have mastered it do they move on to others. After that, higher or more complex competencies are learned to a degree of mastery and isolated from other topics. Another common component of competency-based learning is the ability to skip learning modules entirely if the learner can demonstrate they already have mastery. That can be done either through prior learning assessment or formative testing. Competency-based learning is learnerfocused and works naturally with independent study and with the instructor in the role of facilitator.

The implication of this form of learning to piano pedagogy is that it encourages learners to work on one competency at a time, which is likely a small component of a larger learning goal. Also the learner is can easily move on to higher learning modules or skip learning modules entirely if he can demonstrate competence in a given level. This approach can de-emphasize performance marks interpretation in piano teaching/learning until the learner is considered capable of handling it.

Gann (2014) made a strong case against 'over-notation' thus:

Every composer whose music shows any originality knows, from rehearsal experiences, how inadequate even the most meticulous notation is to get across one's feel for a piece. 
We have no way to represent on paper the momentum of a particular tempo, the nature of an energy level. We have all had experiences in which the tempo was exactly right but the energy all wrong, while someone else might play the passage at a slower tempo but get the energy perfect... In fact, the heavy use of expression markings is tied to a particular conception of music, a conception that carries with it the conceit of the sounds being delicate, precious. Everything proceeds in gestures; wisps of sound crescendo out of nowhere and diminuendo back al niente, the musical continuity always starting and stopping. The sound is supposed to be in constant flux, always either working up toward a climax or moving away from one. This delicate, precious aesthetic has little in common with most of the world's music: mediaeval, African, Asian, vernacular, jazz, or anything else. There is no reason at all that the delicate aesthetic should enjoy a privileged paradigm according to which composers should notate their music.

Gann's case is clear: music can exist in its pure form and still convey meaning. The practice of adorning compositions with weird marks and dynamics came from the post-classical and Romantic ideology- a cultural movement that stressed emotion, imagination, and individualism a cultural movement that stressed emotion, imagination, and individualism. 'Romantic thus came to signify freedom from the Classical tradition and, in its place, the uncontrolled play of the individual creative imagination, with resulting connotations of the highly idiosyncratic and even the fantastic' (The New Harvard dictionary of Music, 2001). Even Beethoven's success has been attributed largely to the fact that he 
put very few subtleties in his music (Glann, 2014). In fact Glann (2014) further submits that:

...while there is plenty of evidence that loads of detail in a score make it more impressive-looking and likely to win awards, there is no evidence at all that audiences love listening to music with loads of detail. The desire for detail is the $20^{\text {th }}$ Century update on the $19^{\text {th }}$ Century academic fallacy, according to which $19^{\text {th }}$ Century fugues are listened to today.

\section{Excerpts of Some Typical Piano Scores}

WOLF'S THEME

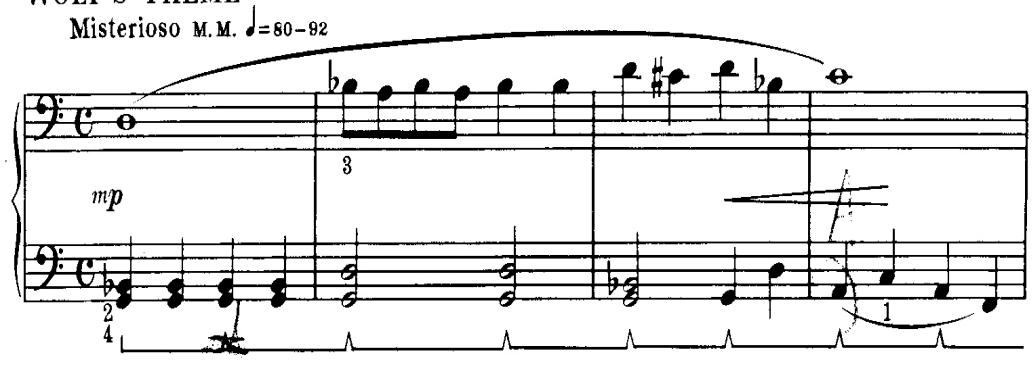


In the meantime, Peter, without the slightest fear, stood behind the closed gate watching all that was going on.

\section{PETER WATCHES}
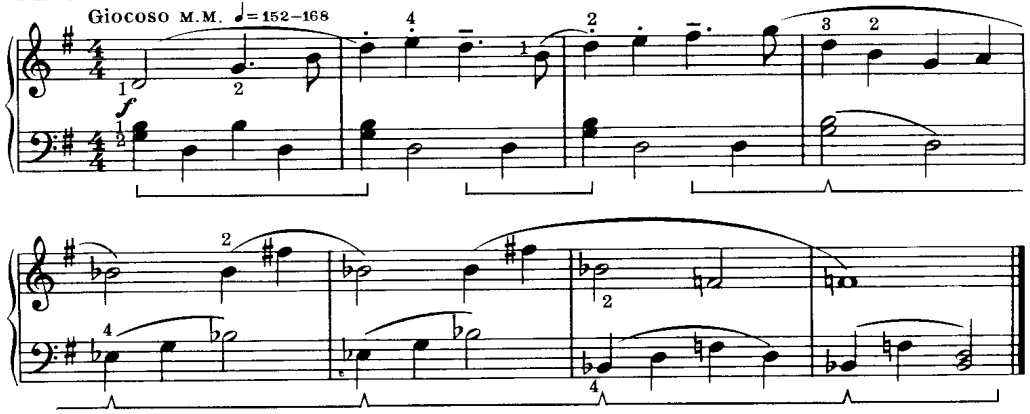

He ran home, took a strong rope and climbed up the stone wall. One of the branches of the tree, around which the wolf was walking, stretched out over the wall. Grabbing hold of the branch, Peter lightly climbed over onto the tree.

PETER CLIMBS INTO TREE
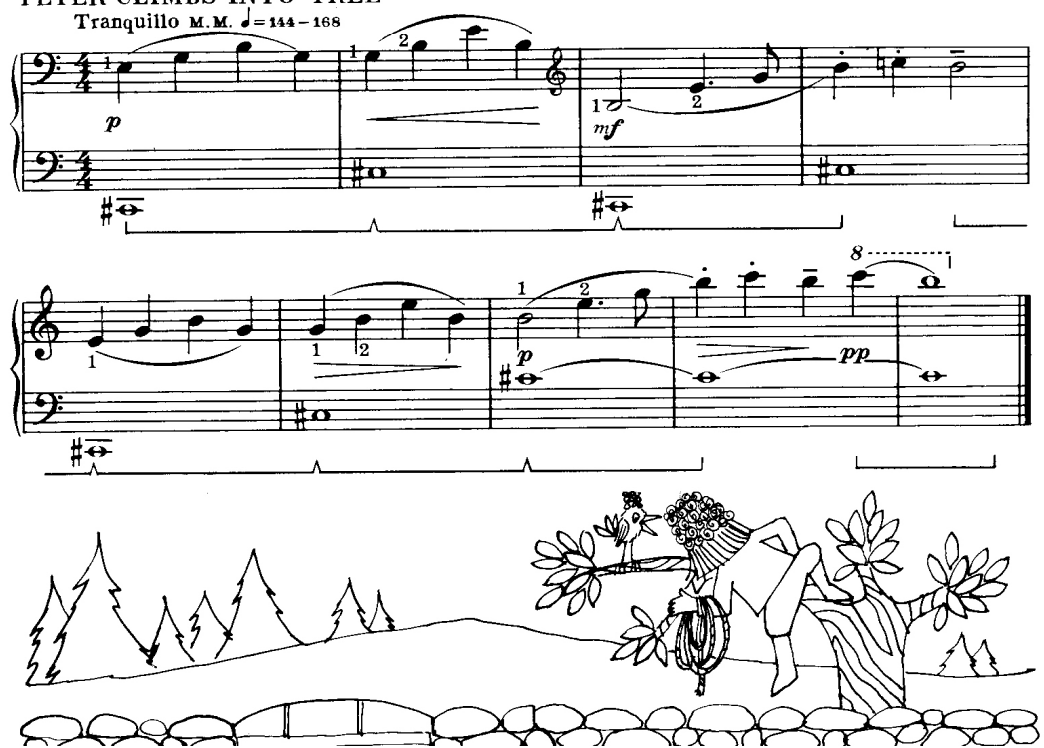


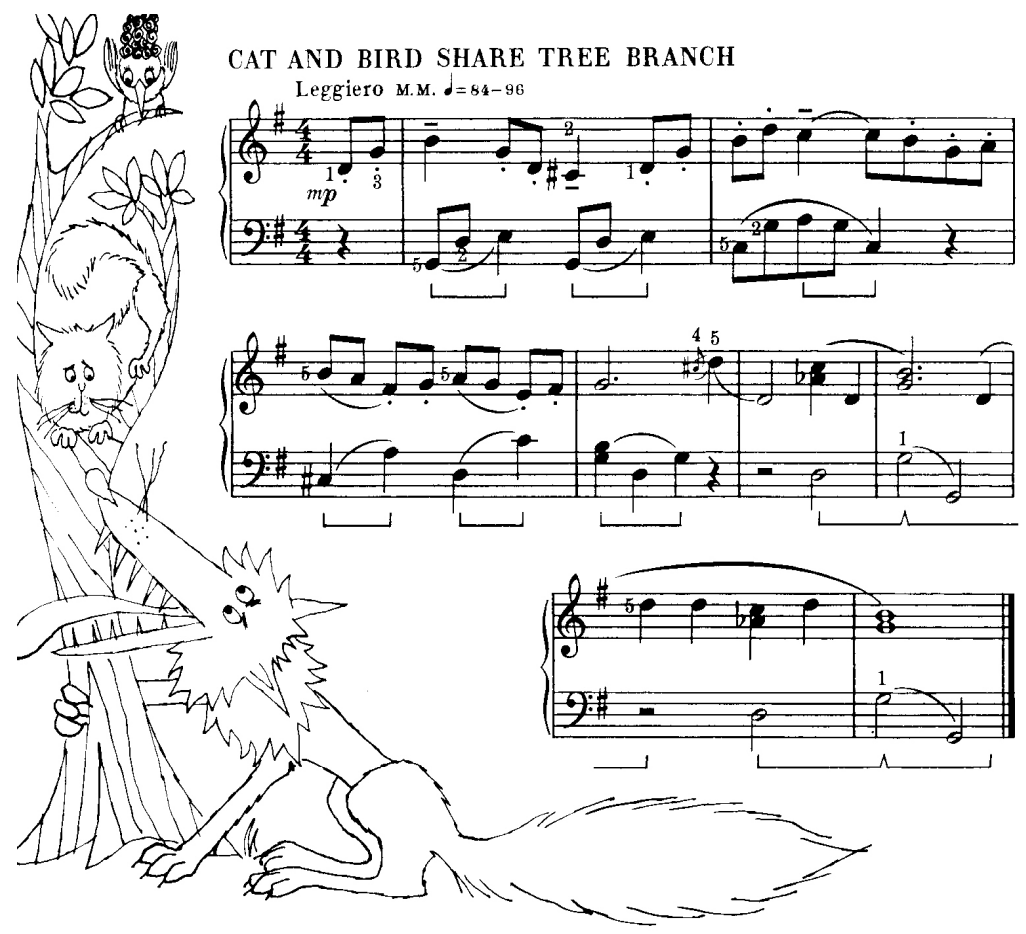

And the wolf walked around and around the tree, looking at them with greedy eyes.

WOLF LOOKS UP GREEDILY
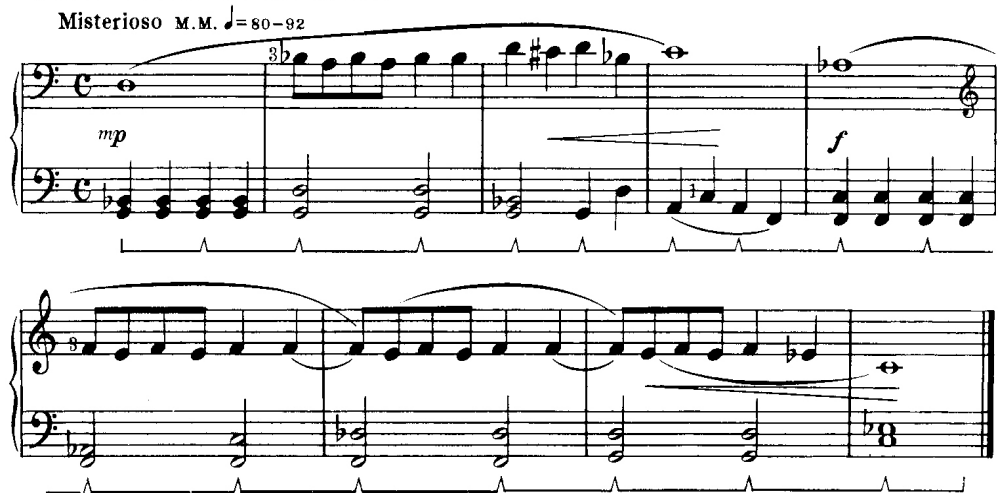


\section{PROCESSIONAL}
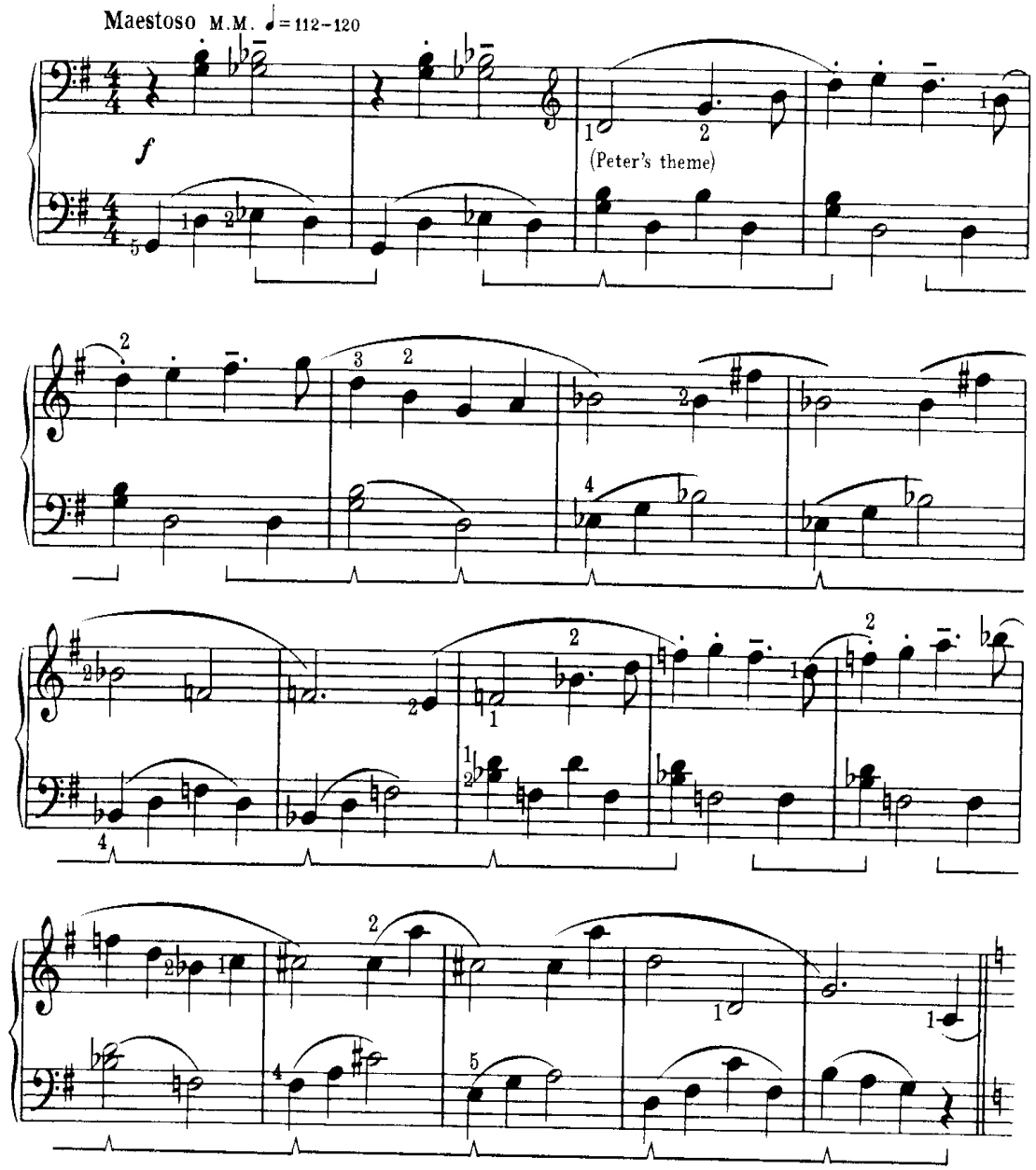


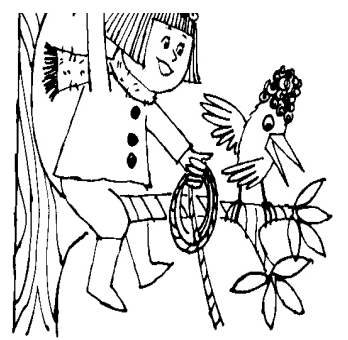

PETER CALLS TO HUNTERS
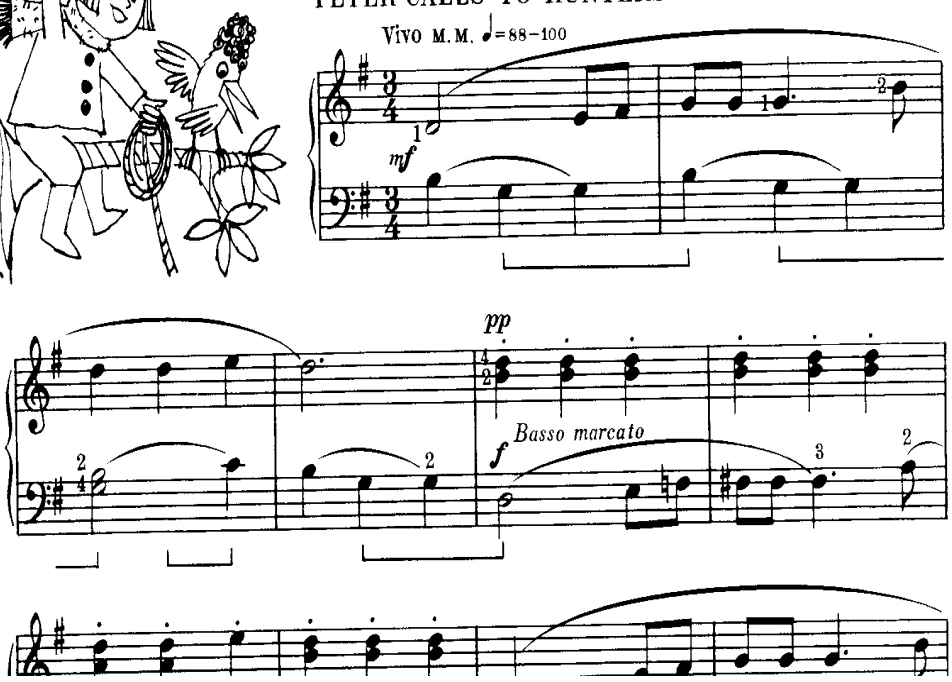

WOLF TRIES TO GET BIRD
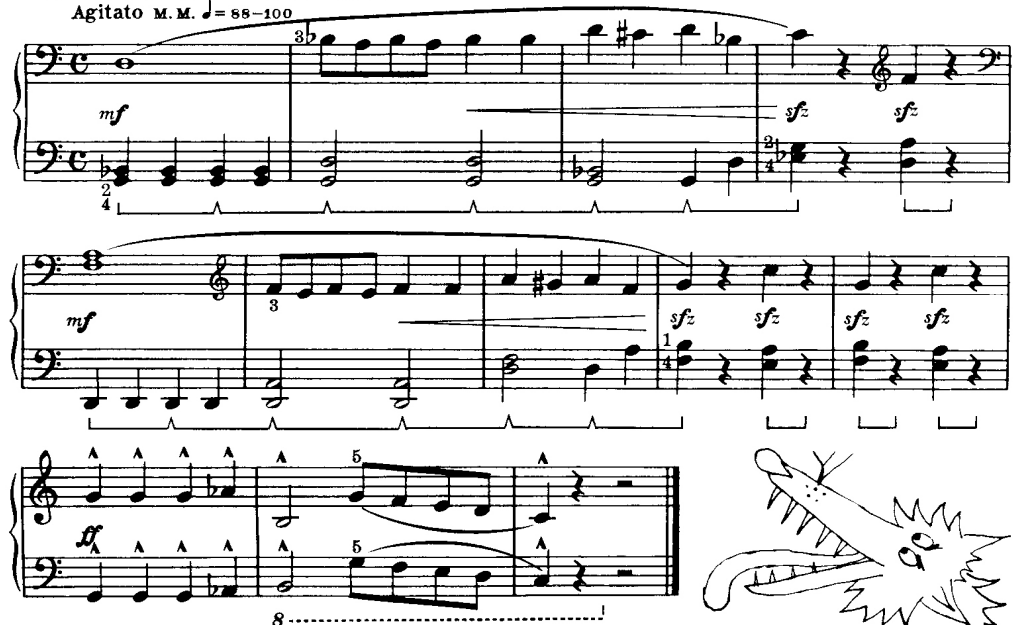


\section{Conclusion}

This paper has called for the application of fundamental musical expression/performance marks for piano-keyboard pedagogy in undergraduate studies in Nigeria. This call was informed by the intricacies and difficulties involved in interpreting certain musical expression/performance marks which were found to be vague and too subjective for piano pedagogy at the undergraduate level.

\section{Ikedimma Nwabufo Okeke \\ Department of Music \\ Nnamdi Azikiwe University, Awka inokeke@unizik.edu.com}

\section{References}

Brown, J. M. (1972). A Handbook of Musical Knowledge ( $3^{\text {rd }}$ Ed.). London: Trinity College of Music.

Gann, k. (2014). The Case against Over-notation: A Defence and a Diatribe.

Kamien, R. (1988). Music: An Appreciation. New York: McGrawHill Book Company.

The New Harvard Dictionary of Music (2001). Randel D. M (Ed).

London: The Belknap Press of Harvard University Press.

http://en. Wikipedia/piano pedagogy [Retrieved: $15^{\text {th }}$ February 2017].

http://en. Wikipedia [Retrieved: $20^{\text {th }}$ February 2017]. 